\title{
Investigating Students' Philosophic-Mindedness through Their Producing Philosophical Questions: Hindering and Facilitating Factors
}

\author{
Gholamhossein Shahini \\ Department of Foreign languages and \\ Linguistics, Shiraz University, \\ Shiraz, Iran \\ ghshahini@rose.shirazu.ac.ir
}

\author{
Zahra Nouri \\ Department of Foreign languages and \\ Linguistics, Shiraz University, \\ Shiraz, Iran \\ za.nouri@gmail.com
}

\begin{abstract}
Given the crucial role philosophical thinking can serve in enhancing the cultivation of mind, it seems urgent that prior to nurturing such thinking its status be investigated within individuals in various educational contexts. Moreover, since philosophy is characteristically a questionraising discipline, one way one's philosophic-mindedness can be investigated is to see if $\mathrm{s} / \mathrm{he}$ is capable of casting a philosophical look at a text, and in turn pose philosophical questions on it. Hence, the present paper aims at a) exploring the participants' ability in making philosophical questions; and b) finding out factors leading to the production or non-production of such questions. To this end, through convenience sampling, a group of $50 \mathrm{BA}$ sophomore and junior students in an EFL context participated in this study. The participants were asked to read two simple short passages, each one about 300 words, and make any type of question(s) (i.e. text-based, beyond the text) that would occur to their mind in essay-type format. Then, using purposeful sampling, 17 out of 50 were selected for an open interview. Based on Cam's (2006) question framework, the findings revealed that the majority of the participants were not able to produce philosophical questions, and the factors leading to generating nonphilosophical questions were memorization-based system, teacher-centered curriculum, undemocratic atmosphere of classes, unsuitable family environment, weak role of the mass media, and irrational social customs among others. On the contrary, the factors enabling the production of philosophical questions were innate disposition towards thinking, introversion, appropriate family environment, proper nurturing conditions, and appropriate methods of teaching. Furthermore, the technique of question-making and question-analysis together with a question framework are introduced to be employed for realizing philosophic-mindedness. Finally, Philosophy-based Language Teaching is suggested as an approach for removing the obstacles to philosophical thinking.
\end{abstract}

Keywords: Cam's question framework, EFL, Philosophic-mindedness, Philosophical questions, Philosophical thinking

\section{INTRODUCTION}

Philosophy, or 'love of wisdom', according to Lipman (1988), does not imply abstract argumentations and doctrines among great philosophers such as Plato and Aristotle, nor does it intend to teach the subject Philosophy to sophisticated bookish minds in university lecture halls. Philosophy from Lipman's perspective, is identified with the activity of philosophizing which includes questioning, reasoning and arguing. Philosophy, as such, "encourages people to puzzle and question, to hypothesize and explore" (Cam, 1995, p. 15). Philosophy, as Splitter 
and Sharp (1995) indicate, is viewed as a tool whose aim is to make people enquire into the essence of phenomena and concepts. According to Haynes (2002), "such concepts are wideranging and include issues like friendship, anger, life and death, religious beliefs, fairness, etc." (p. 23). Accordingly, philosophy assists the practice of looking into those concepts and questions most of us have wondered about from time to time: "What is reality, beauty democracy, justice, art, truth, language, or does everything have a cause? What makes something beautiful?" (Gregory, 2008, pp. 2-3). Questions of this type are known as philosophical questions.

Philosophical questions, according to Lipman, Sharp and Oscanyan (1980), have the following characteristics which target:

- Concepts/metaphysics (e.g., What is beauty?)

- Whatness/ontology (e.g., What is God?)

- Existence (e.g., Does God exist?)

- Knowledge/epistemology (e.g., How do we know if God exists?)

- Ethics/values (e.g., Is that good, right, etc.?)

- Logic/reasoning (e.g., If so...then...?).

On the one hand, given the crucial role philosophical thinking can play in enhancing the cultivation of mind in routine life, in general, and in educational and/or academic settings, in particular (Hashemi, 2014; Inggårde, 2014; Jie et al. 2014; Preece, 2013), it seems urgent that prior to nurturing such thinking, its status be investigated within individuals in different contexts. Accordingly, as Lipman (1993) states, "since philosophy is characteristically a question-raising discipline" (p. 677), one way one's philosophic-mindedness can be investigated is to see if s/he is able to cast a philosophical look at a text and in turn to pose philosophical question(s) on it. Needless to say, however, that a person who has adopted the habit of philosophical thinking, that is, critically puts the basic and deep-seated beliefs into question; does not lead an unreflective life based on biases and habitual beliefs (Russell, 1997); and tends to delve into the depth of wide-spread concepts mentioned above, her/his questions differ from those routine/superficial ones posed by the ordinary people.

On the other hand, since the issue of determining one's philosophical ability through producing philosophical questions is almost new in educational arenas, in general, and in EFL contexts, in particular, no attempt has so far been made to explore students' potentialities from this perspective. Therefore, using this technique and Cam's (2006) question framework, it is hoped that policy makers, curriculum-planners, textbook developers, and instructors may become aware of their students' philosophical thinking status. Besides, it is hoped that the results of the present research can assist the stakeholders in the EFL context of Iran to get acquainted with the corresponding factors leading to (non-) philosophical thinking ability.

\section{Cam's Question Framework}

According to Cam (2006), the questions that are prompted by reading a text can be classified into four types which are vividly depicted in Figure 1 on the following short text adopted from him.

Pooh and Piglet can be seen trudging along a snowy track. The day is clear but the sun is low and it casts a yellowish-orange glow over the scene. Piglet is wrapped in woolens and a scarf, while Pooh has nothing on but an old short-sleeved top that is several sizes too small for him. Piglet says to Pooh touchingly, 'We'll be friends forever, won't we Pooh?' 'Even longer' Pooh replies (p. 32). 


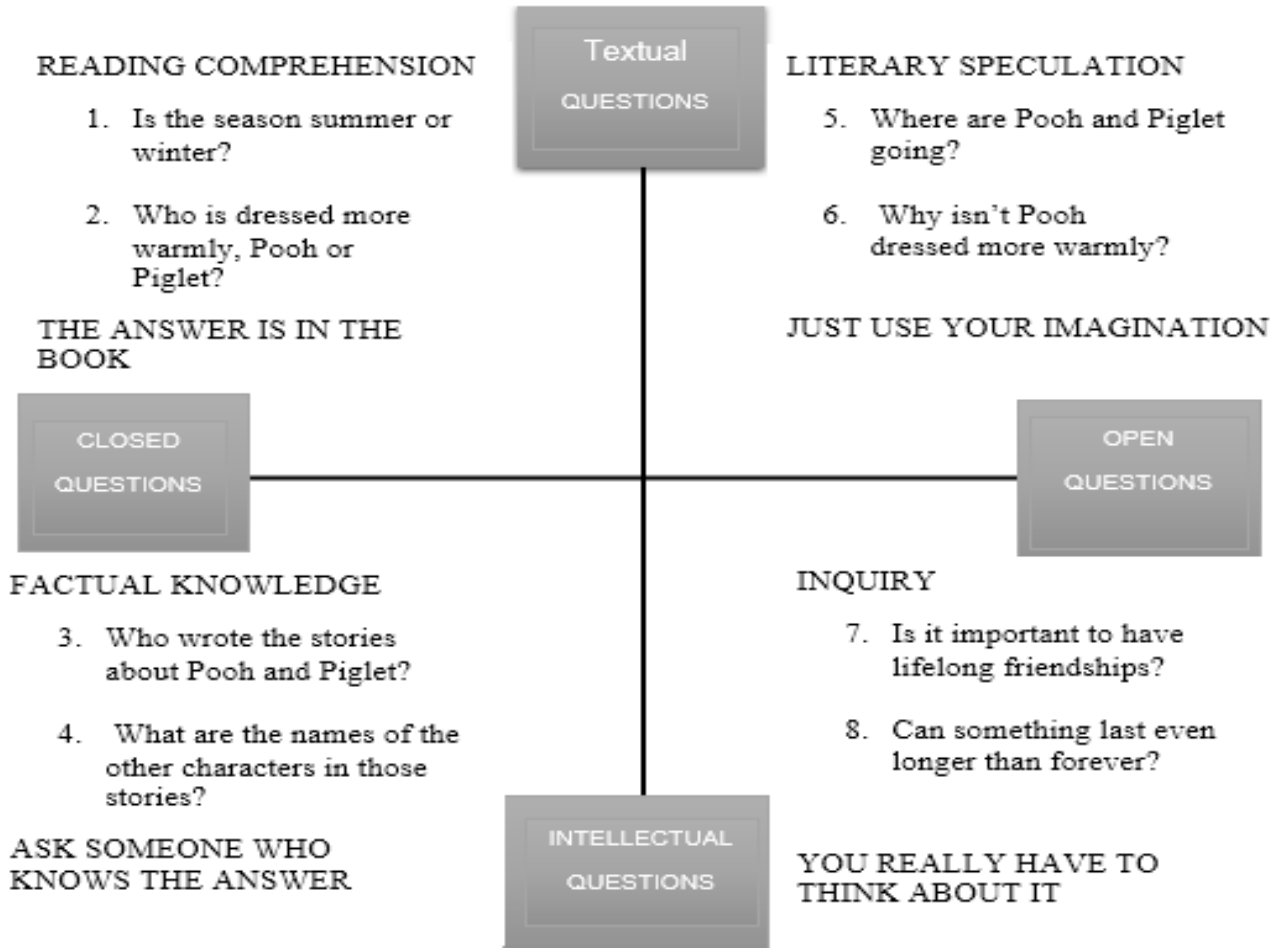

Figure 1. Cam's framework on different types of questions (Adopted from Cam, 2006, p. 34)

The afore-cited questions can be divided into 'closed' and 'open' questions. Closed questions are the ones for which there is a settled answer. The answer might need a little research, but definitely there will be one single established answer which leaves no room for discussion. Two types of closed questions can be 'reading comprehension' and 'factual' questions. Reading comprehension questions (Qs. 1,2) are those whose answers can be found in the text. Factual knowledge questions (Qs. 3, 4) ask for reasonably simple, straight-forward answers based on general information and obvious facts. Such questions can be answered by a teacher, a textbook, and a web search.

Open questions, on the other hand, have no single correct answer, although some answers might be more appropriate or more reasonable than others. Such questions are about many things that are indeterminate in a text. They invite thinking and leave a lot of room for interpretation, guessing, and varying points of view. One type of these questions is called 'literary speculation' (Qs. 5, 6). For instance, it is not explained why Pooh is wearing this top on such a cold day. We might be left to guess the possibilities.

The two final questions (Qs. 7, 8) are open questions that look into the 'big' picture and explore the issues on a larger scale. They are totally detached from the text and take us from the story to general issues. That is, they do not target the story characters or what is taking place in the story, but seek to uncover the basic concepts and broad themes forming the structure of the story. These questions which are known as enquiry/philosophical, engage us in enquiries or negotiations in which one is provoked to reason and evaluate alternative perspectives. Responding to such questions requires the use of some criteria. These criteria are verifying assumptions, making inferences, and examining concepts.

The theoretical background underlying the last part of the framework, which is the primary concern of this study, relies on Dewey's (1983) reflective thinking and Lipman's (2003) philosophical thinking. Reflective thinking appears when we are seeking for a resolution to a problem which has led to our perplexity, puzzlement, and wonder. The urgent need for 
reflective thinking is felt when we encounter problems and dilemmas. This sort of thinking is the ability to reflect on everything we encounter to examine the consequences of our ideas and look for likely causes and possible reasons to come up with a solution. Philosophical thinking, however, draws more heavily on philosophy, a discipline that pays a great deal of attention to "uncovering conceptual boundaries and connections, discovering criteria, defining terms, classifying objects, identifying logical relations, drawing deductive inferences, and constructing analogies" (Cam, 1995, p. 16).

\section{Objectives of the Study}

The present research, using Cam's (2006) question framework and its underlying theoretical background, intends a) to investigate EFL students' philosophical thinking status via their casting a philosophical look at issues and raising philosophical questions; and b) to find out the factors leading to (not) generating such questions. Hence, the research questions specifically are:

1. Are the questions produced by the participants philosophical?

2. What factors lead to the participants' production or non-production of philosophical questions?

\section{LITERATURE REVIEW}

Up to the present, the issues related to the status of philosophical thinking (not the status of critical, creative, caring or other types of thinking) are very rarely addressed. The only ones, to the best of our knowledge, are those performed within Smith's (1965) framework. Inspired by that, the philosophic-mindedness of managers, trainers, and supervisors in various sports teams in Iran was examined by Talebpour et al. (2005). In this research, using random-stratified sampling, 250 subjects participated from all universities. The data collection tool was Soltani's (1996) philosophical mindset questionnaire. The questionnaire consisted of 60 Likert-scale questions related to three characteristics of comprehensiveness, penetration, and flexibility. Comprehensiveness is seeing objects as a whole, taking all options into account upon confronting them, and not holding dichotomous, binary view towards phenomena. Penetration is delving into every single choice till you reach their depths. And, flexibility means swinging among the choices dwelled on in the two previous stages and selecting the more reasonable one(s). The results revealed a moderate level of philosophical mentality among the participants. But the managers possessed a higher degree of philosophical mindset. In addition, among the three aspects of philosophic-mindedness, the highest mean score belonged to penetration.

To evaluate the sports teachers and trainers' philosophical mentality, a descriptivecorrelational study was carried out by Nikkhah (2008). Using convenience sampling, 75 sports teachers and trainers in Golpayegan, Iran, took part in the study. Inspired by Smith (1956), the philosophical mentality questionnaire made by Soltani (1996) was utilized. The findings disclosed that the sports teachers and trainers' philosophical thinking ability was moderate. Moreover, the sports teachers' mean score was higher than that of the sports trainers. Among the three dimensions mentioned above, comprehensiveness achieved the highest score. In addition, education served a key role in improving the participants' philosophic-mindedness.

Additionally, Nouri et al. (2013), as one part of their research, examined third grade male and female students' philosophic-mindedness in Hamedan junior high schools, Iran. Among 8229 students, 367 were chosen via stratified sampling. A researcher-made questionnaire, based on Smith's (1956) framework, was used as an instrument for data 
collection. The instrument's Cronbach's alpha reliability index was .86 . The findings portrayed that in comparison to male students' philosophic-mindedness, that of female students was higher. Furthermore, females outperformed males in all three components of comprehensiveness, penetration, and flexibility.

And finally, Ghorbanalizadeh Ghaziani et al. (2014) examined the philosophicmindedness preferences of Iranian physical education and sports science lecturers using Soltani's (1996) philosophic-mindedness questionnaire as the instrument. Of the 150 randomly distributed questionnaires in state universities, 123 completed questionnaires were returned to the researchers and 98 were ratified. Based on the findings, the participants' philosophicmindedness preferences were comprehensiveness, penetration, and flexibility in order. Accordingly, it was concluded that there was no balance in the three components of philosophic-mindedness among the lecturers, and that the three components need to be evenly developed within the participants so that they gain a profound philosophical outlook in life. Taking account of the published literature, one notices that the above studies are all quantitative (survey-based) research which have attempted to assess the participants' philosophicmindedness and preferences in various disciplines by employing Smith's $(1956,1965)$ framework. The present research, however, is qualitative and is based on Cam's (2006) framework. Using content analysis, the study intends to evaluate the students' philosophical mentality from a new perspective. That is, as the first attempt, it seeks to examine the participants' philosophic-mindedness through analyzing the questions they have generated.

\section{METHODOLOGY}

\section{Design}

The design of the current study is qualitative using content analysis and open interview.

\section{Participants}

The participants were selected based on convenience sampling. A group of 50 BA sophomore and junior EFL students (31 females and 19 males) at Shiraz University, Iran participated in the study. The participants aged 19 to 30 . Using purposive sampling which was conducted based on their production of different types of questions, 17 participants ( 9 females and 8 males) out of 50 were selected for interview. The number of interviewees was determined by the level of data saturation reached.

\section{Materials}

Two simple short passages of different types, story and non-story, with the potentiality of being subjected to philosophical investigation were utilized. Two texts were used so that the participants could have enough chance to pose further questions and were of different types to provide them with ample opportunity to raise questions on two varying themes. Simple passages were chosen to make them easy to understand.

The philosophical potentiality of the passages was verified by two experts in the field of philosophy and philosophy of education. The experts were asked to read the texts and then write a number of philosophical questions on them if they would think the texts could be viewed from a philosophical perspective. Doing that, they confirmed that open questions including enquiry/philosophical questions, could be made on the two texts and consequently the texts 
could be inspected philosophically. The texts were: 1) The Tale of Peter Rabbit (Potter, 1902) which has been translated into 36 languages and with 45 million copies sold is one of the bestselling books (see Appendix A). It is worth mentioning that although this story is written for children, people at any age can view the story from different perspectives. 2) Ladan and Laleh Bijani ('Ladan and Laleh Bijani,' n.d.) which is a real life report of two Iranian Law graduate conjoined twin sisters, joined at the head, who decided to get separated but died after their complicated surgical operation (see Appendix B).

\section{Data collection and data analysis procedure}

The participants were asked to read the two passages and make any type of question(s) (closed/routine/superficial/text-bound questions and/or open/beyond-routine or beyond-thetext questions including deep, reflective, thought-provoking, inferential, critical, creative, philosophical questions, and the like) that would occur to them in essay-type format. To stress the point that the participants were free to pose any type of question(s), they were repeatedly reminded throughout the text-reading and question-making phases that there was no restriction to their question making in terms of number and content. Text reading together with question making lasted about two hours. Based on the definition of different types of questions in Cam's (2006) framework and the characteristics of philosophical questions provided earlier, the contents of all questions were first analyzed and later classified into four categories. The questions were evaluated by the two present researchers individually and the inter-rater reliability was 0.93 . To increase the study's credibility and confirmability, the questions were also validated by the experts in the field of Philosophy and Philosophy of Education to verify the classification of questions performed by the present two researchers. The frequency of each type of question is depicted and the results are descriptively reported and discussed.

Among 17 participants who were selected for interview, 13 were those who had raised closed questions and 4 had posed open questions with more emphasis on enquiry/philosophical questions. To remind them of their previous performance, they were shown the questions they had made on the two passages. Since they were not totally aware of the nature of enquiry/philosophical questions, they were given a) a three-page explanation on the essence of philosophical questions and b) a complete list of philosophical questions made by Kennedy (1992) on The Tale of Peter Rabbit plus a series of philosophical questions on the text of Laleh and Ladan. In order to provide them with enough opportunity to thoroughly get acquainted with these printed materials, they were asked to take them home and carefully read them. After comparing their own questions with those enquiry/philosophical questions, they were interviewed to share their viewpoints for their non-/production of enquiry/philosophical questions. It should be noted that before the interview got started, they were asked a few questions on the nature of philosophical questions to ascertain if they had achieved an adequate knowledge of the idea. An open interview, individually and face-to-face in Persian, opened with a single question, namely, 'What factors led to your (not) raising philosophical questions?' The forthcoming questions were then raised based on the responses provided by the interviewees. The interviews were accomplished in Persian so that the participants would feel more relaxed, comfortable, and secure to express themselves. In addition, it would help eliminate likely misunderstandings. The participants were ensured their anonymity would be preserved. The time of each interview lasted about one hour and a half. The length of the time varied depending on the situation, the participants' cooperation and the information they supplied. To avoid tiredness, participants were given a ten-minute rest or coffee break. During the interview, to elicit relevant, to the point, and deeper information, key words were noted, targeted, and questioned in later probes. The participants' responses were audio-recorded, transcribed, and then analyzed. The key points were culled, categorized, and then translated 
into English. It should be added that the credibility (truth value) of the data was obtained through consensus, using peer review or peer debriefing. To clear up miscommunications, identify inaccuracies, assist the researchers obtain extra useful data, and to increase the study's credibility and confirmability, member check/participant feedback was used as well. The dependability of the data was obtained by coding agreement. The inter-coder agreement between the two researchers was found to be 0.88 . The remaining differences were resolved through further discussions.

\section{RESULTS AND DISCUSSION}

With respect to the first research question, the questions made by the participants were classified as closed and open in Table 1 as follows:

Table 1

Type and number of questions made by the participants

\begin{tabular}{|c|c|c|c|c|c|}
\hline \multirow[b]{2}{*}{ Participants } & \multirow[b]{2}{*}{$\begin{array}{c}\text { Age/ } \\
\text { Sex }\end{array}$} & \multirow[b]{2}{*}{$\begin{array}{l}\text { No. of } \\
\text { closed } \\
\text { Qs. }\end{array}$} & \multicolumn{2}{|c|}{ No. of open Qs. } & \multirow[b]{2}{*}{ Total } \\
\hline & & & $\begin{array}{c}\text { No. of } \\
\text { literary } \\
\text { speculation } \\
\text { Qs. }\end{array}$ & $\begin{array}{c}\text { No. of enquiry/ } \\
\text { philosophical } \\
\text { Qs. }\end{array}$ & \\
\hline Participant1 & $35 / \mathrm{F}$ & 17 & 5 & 0 & 22 \\
\hline Participant2 & $21 / \mathrm{F}$ & 11 & 11 & 1 & 23 \\
\hline Participant3 & 23/M & 22 & 0 & 0 & 22 \\
\hline Participant4 & $21 / \mathrm{M}$ & 21 & 2 & 1 & 24 \\
\hline Participant5 & $27 / F$ & 19 & 0 & 1 & 20 \\
\hline Participant6 & $32 / \mathrm{F}$ & 20 & 0 & 1 & 21 \\
\hline Participant7 & $21 / \mathrm{F}$ & 21 & 0 & 0 & 21 \\
\hline Participant8 & $21 / \mathrm{F}$ & 17 & 0 & 2 & 19 \\
\hline Participant9 & $22 / F$ & 19 & 0 & 0 & 19 \\
\hline Participant10 & $20 / F$ & 17 & 0 & 1 & 18 \\
\hline Participant11 & $24 / \mathrm{M}$ & 11 & 13 & 0 & 24 \\
\hline Participant12 & $26 / \mathrm{M}$ & 19 & 0 & 1 & 20 \\
\hline Participant13 & $22 / \mathrm{F}$ & 21 & 0 & 1 & 22 \\
\hline Participant14 & $21 / \mathrm{F}$ & 16 & 4 & 0 & 20 \\
\hline Participant15 & $19 / \mathrm{F}$ & 19 & 2 & 1 & 22 \\
\hline Participant16 & $23 / \mathrm{F}$ & 22 & 0 & 1 & 23 \\
\hline Participant17 & $21 / \mathrm{M}$ & 18 & 0 & 0 & 18 \\
\hline Participant18 & $22 / \mathrm{F}$ & 21 & 1 & 1 & 23 \\
\hline Participant19 & $20 / \mathrm{F}$ & 17 & 4 & 1 & 22 \\
\hline Participant20 & $20 / \mathrm{M}$ & 22 & 0 & 0 & 22 \\
\hline Participant21 & $20 / \mathrm{F}$ & 17 & 4 & 0 & 21 \\
\hline Participant22 & $20 / \mathrm{F}$ & 20 & 2 & 2 & 24 \\
\hline Participant23 & $21 / \mathrm{F}$ & 19 & 0 & 1 & 20 \\
\hline Participant24 & $23 / \mathrm{F}$ & 20 & 0 & 1 & 21 \\
\hline Participant25 & $26 / \mathrm{M}$ & 23 & 0 & 0 & 23 \\
\hline Participant26 & $20 / \mathrm{F}$ & 14 & 9 & 1 & 24 \\
\hline Participant 27 & $19 / \mathrm{F}$ & 18 & 6 & 0 & 24 \\
\hline Participant 28 & $21 / \mathrm{F}$ & 18 & 0 & 0 & 18 \\
\hline Participant29 & $22 / \mathrm{F}$ & 12 & 8 & 1 & 21 \\
\hline Participant30 & $21 / \mathrm{F}$ & 21 & 0 & 1 & 22 \\
\hline Participant31 & 20/M & 22 & 3 & 2 & 27 \\
\hline Participant 32 & $22 / \mathrm{F}$ & 19 & 3 & 0 & 22 \\
\hline Participant 33 & $20 / \mathrm{F}$ & 24 & 2 & 0 & 26 \\
\hline Participant34 & $45 / \mathrm{M}$ & 24 & 2 & 1 & 27 \\
\hline Participant35 & $21 / \mathrm{M}$ & 19 & 0 & 0 & 19 \\
\hline Participant36 & $21 / \mathrm{M}$ & 16 & 6 & 1 & 23 \\
\hline Participant37 & $23 / \mathrm{F}$ & 9 & 14 & 1 & 24 \\
\hline
\end{tabular}




\begin{tabular}{cccccc} 
Participant38 & 23/F & 11 & 16 & 0 & 27 \\
Participant39 & 24/M & 7 & 11 & 1 & 19 \\
Participant40 & 20/M & 18 & 0 & 0 & 18 \\
Participant41 & 20/F & 15 & 4 & 1 & 20 \\
Participant42 & $22 / \mathrm{F}$ & 13 & 2 & 0 & 15 \\
Participant43 & $23 / \mathrm{M}$ & 20 & 2 & 1 & 23 \\
Participant43 & $21 / \mathrm{M}$ & 17 & 0 & 2 & 19 \\
Participant44 & $28 / \mathrm{M}$ & 3 & 52 & 0 & 55 \\
Participant45 & $19 / \mathrm{M}$ & 16 & 11 & 2 & 29 \\
Participant46 & $23 / \mathrm{M}$ & 21 & 0 & 0 & 21 \\
Participant47 & $27 / \mathrm{M}$ & 19 & 3 & 1 & 23 \\
Participant48 & 20/F & 17 & 2 & 0 & 19 \\
Participant49 & $21 / \mathrm{F}$ & 23 & 2 & 1 & 26 \\
Participant50 & 27/F & 10 & 9 & 2 & 21 \\
\hline Total & & 896 & 215 & 36 & 1147 \\
\hline
\end{tabular}

As it is illustrated, $896(78 \%)$ of the questions are closed, and in some cases, all the questions raised by a single participant are of this type. In contrast, $215(19 \%)$ of the questions are literary speculation and $36(3 \%)$ are enquiry/philosophical which is more vividly portrayed in Figure 2:

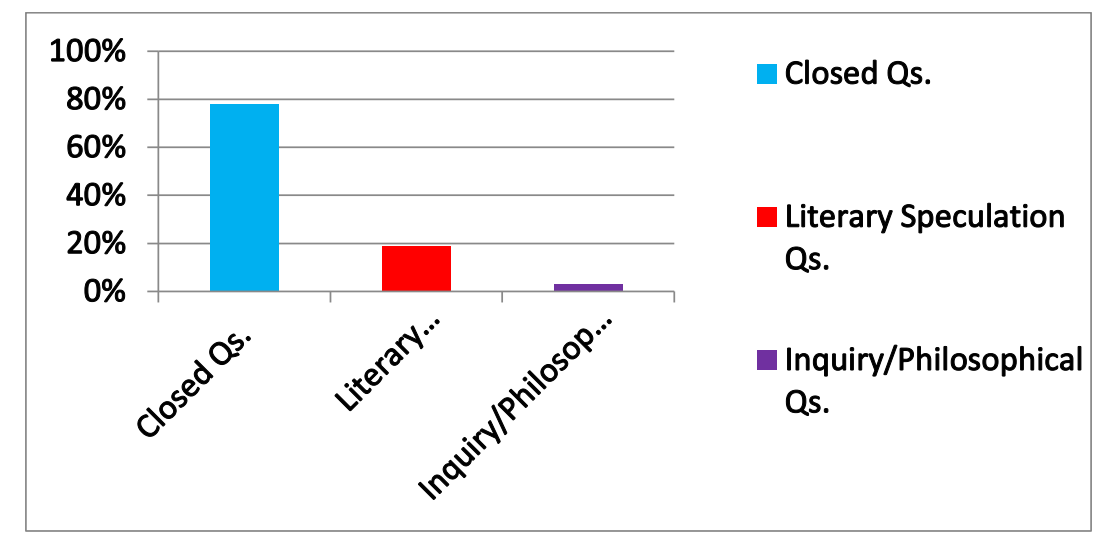

Figure 2. The percent and type of questions made by the participants

For further illumination, a sample of different types of questions made by the participants on the tale of Peter Rabbit is reflected below:

\section{Reading comprehension questions}

1. Where did Peter go after leaving the house?

2. What finally happened to Peter?

3. How did the mouse respond to Peter's question?

4. What was McGregor planting?

\section{Literary speculation questions}

1. Should Peter feel ashamed of what he has done?

2. Do you think Peter will repeat the adventure?

3 . Which of the rabbits do you like to grow your child with?

4. Was Peter curious or a bad boy?

\section{Enquiry/philosophical questions}

1. Is it right to call a boy, 'thief'?

2. How do you know when something is a theft?

3. Do you think crying in a frightening situation solves any problems?

4. Does being in a rush solve any problem? 
As to the above closed questions, one can easily find them text-bound for their answers can be quickly searched throughout the texts. In other words, they are neither thoughtprovoking nor do they show the students have been able to see beyond the texts. This finding seems to be partly in line with Lipman's (1993) words who believes that university students do not think reflectively or there is schooling without thinking. The finding is also in conformity with what Orlich, Harder, Callahan, Trevisan, and Brown (2010) found that college students raise questions and share discussions at low and information-based level.

Compared with closed questions, the above literary speculation questions were realized based on the features presented in the related section of the framework. The sample questions are targeting the characters in the texts, yet their responses cannot be explicitly found in the texts. That is, they are partially detached from the texts. This implies that the texts have made the students think and find points puzzling, peculiar, and odd in some way. Indeed, they have aroused the students' curiosity up to a level that their answers cannot be settled by reference to the texts, established facts, or even their learning. Students' tendency to delve into the texts and raise deep questions could be traced in their willingness not to restrict themselves to the surface. They appear to be willing to discover what is behind the facade, to analyze and evaluate, and to benefit from a more complete understanding so as to see what (additional) insights can be gained and what alternatives and possibilities might be guessed.

However, the enquiry/philosophical questions were identified based on the criteria put forward in the last part of the framework and the characteristics of philosophical questions listed earlier. These questions show the students' deeper understanding and their probing into the nature of concepts. In fact, the questions, according to Cam (1995), have gravitated to pure philosophy, that is, they have demonstrated the increasing generality of the issues which are totally detached from the texts. For example, the question 'Do you think crying in a frightening situation solves any problems?' has nothing to do with the text and can be answered without reading the text. In addition, based on the features of philosophical questions, the question 'Is it right to call a boy thief?' targets value (right). Or the question 'How do you know when something is a theft?' questions two points at the same time: epistemology (know) and the concept of 'theft'.

Given the second research question, the factors which caused the students to raise or not to raise philosophical questions were classified into hindering and facilitating ones.

\section{Hindering factors}

As to the inhibiting factors, of 13 participants, the majority revealed that they were demanded by their teachers to memorise materials for their exams. They indicated that they had no chance to relate materials to their real lives. They added that they were not educated to cogitate over contents and to analyse them critically. For instance, it was divulged by participant 7 that: "In all levels of education (from primary school to university) our minds are injected with a certain set of fixed facts, clichés, and stereotypes. In our system of education, we memorise content and then take exam(s)."

In line with this point, Mollaei Nejad and Zekavati (2008) hold that the present orientation of education in Iran is progressively pushing students to memorise contents such as geography, history, literature, theology, and the way they are taught fails to flourish their ability to show reflection. 
Another factor the participants referred to was that in their L2 reading comprehension classes, it was usually a norm to raise and answer text-based questions and that discussing thought-provoking questions was regarded as something bizarre. They noted that the educational system has dried up the roots of criticizing and turned schools into dogmatism training centers. Participant 15 in this respect said: "We are usually anticipated to make textbound questions after reading a text. This can be attributed to the teachers' lack of authority on the subjects as they do not permit students to step beyond the printed materials".

As Lipman (2003) points out, text-bound questions can be the consequence of the policy made by curriculum planners, teachers, and test makers. Another factor they referred to was the closed and non-liberal atmosphere of classes. This point, according to them, could be ascribed to the teachers' narrow-minded behavior that did not let students express their viewpoints in classes freely. They stated that some teachers were like dictators who did not allow students to ask thought-provoking questions and if they did, the teachers either got angry or retaliated when correcting their exam papers. For example, participant 3 disclosed that: "In our educational system, we are not free to express our ideas. We are not permitted to discuss and challenge issues. Our academic environment is quite similar to a military environment." They added that sometimes teachers were not at fault because they were restricted by authorities. In simple words, they had to follow what they were prescribed to do.

According to participant 17:

\section{"Teachers, even if they are interested, are afraid of providing students with opportunities for discussion and negotiation. In my opinion, they are dictated by the authorities to stick to the contents of the textbooks and not to go beyond their limits."}

In accord with the above points, Haynes (2002) argues that teaching is highly regulated and strictly controlled by the details issued from the official curriculum, and teachers are obliged to satisfy the demands ordered by authorities. Thus, the adopted policy tacitly prohibits teachers from making room for open discussions. It is obvious, however, that the more restriction set on the teachers, the less effective thinkers they become which in turn gives rise to their inefficiency (Hager \& Kaye, 1991).

Proclivity towards superficiality was another factor addressed by some participants. They noted that their personality trait did stop them to make an effort to search for the hidden layers of meaning beneath a subject, to seek for the underlying assumptions, and to find solutions as to why and how they have occurred. For instance, participant 14 said: "I personally do not like to burrow beneath the surface of the issues and think deeply over them... my concern is surface, appearance, skin, and form not depth, content, substance, and inward structure."

In step with the above remark, Cottrell (2005) argues that personality traits affect one's thinking ability, and one who is willing to be superficial does not demonstrate any interest in digging beneath the surface to understand more. Another inhibiting factor was family. Most participants mentioned that parents were not only incapable of but also inattentive and indifferent to developing their thinking power. They also recounted that some parents were neither familiar with thinking skills nor were they aware of their significance and if they were, due to the meager attention paid to those skills by the educational system, they had little or no chance to nurture them within their children. 
Participant 6 in this regard maintained:

"My parents do not look at issues deeply and thoughtfully. They have raised me in the same way. That is why I am a superficial person. Moreover, they are so busy that they scarcely find enough time for my education."

In step with the above statements, Duncan and Brooks-Gunn (1997) hold that as parents are children's first teachers, their intellectual passivity or thinking incapability will most likely be passed down to them. The weak role of mass media in constraining their thinking ability was another issue. They asserted that television provides its viewers with films and series that mainly show the daily life of the ordinary people without encouraging the viewers to contemplate on their themes. They added that media are not allowed to call some issues into question or to seek alternative opinions on them.

According to participant 15:

"The media act according to the desires and prejudices of their audience and by telling people what they want to hear make profit and that media are used to spread the ideologies of the government or the worldviews of the ruling class."

In harmony with the afore-cited points, Kincheloe and Weil (2004) express that we sometimes become so caught up in media programs that we fail to critically question their aims and messages. And Paul and Elder (2005) explain that the fundamental purpose of mass media is not to educate people or to invite them to think, but to make a profit. Prohibitions rooted in socio-cultural issues and traditional customs were among the inhibiting factors as well. In this regard participant 10 articulated that: "We inhabit a society where criticism and free expression of ideas are not welcomed. It is partly due to our traditions, customs, and culture."

They elucidated that Iran, as a several thousand-year-old country, is replete with numerous customs, and that nearly every act in this country is tied with a tradition and ethnic value. They asserted that at least half of these customs are not rationale-based and are inherently not in compliance with logic and reason. Therefore, since throughout many years customs have brought with themselves passion and sensation, this may have been considered as a reason why thinking is neglected and why beyond-routine questions do not come to mind. In proportion to the aforesaid points, Mead (1934) discloses that since peoples' minds are molded by sociocultural customs, their way of thinking is ruled by their dominant environment.

Another hindering factor which was mentioned was the essence of (philosophical) concepts. Based on their explanations, the participants pay scant or no attention to such concepts. Participant 12, for instance, attested that: "I have predetermined definition(s) of concepts in my mind. I feel no need to think about them or put them into question."

Or participant 1 accounted:

"We every day hear concepts like freedom, culture, education, language, injustice, etc. but we are indifferent to their essence and meaning. People, for example, talk about flowers and their beauties but usually do not ask themselves: 'What is beauty?', 
The interviewees singled out that fixed, predefined definition(s) of concepts had already been shaped in their minds out of their experiences, dictionary definitions, and by others like their parents, teachers, and friends. Hence, they felt no need to probe into concepts and to create a conceptualization to delve into their (new) deep layers of meaning. Similarly, it is interesting to know that Paul and Elder (2012) believe that concepts are like the air everywhere but we rarely notice them. The participants also stated that they were reluctant to challenge (philosophical) concepts because they are complex. Participant 2 said: "... and it's difficult to challenge and define concepts. They are intangible and complicated. Indeed, I confess I don't take notice of them in books and texts."

Basically, some concepts, as Cam (1995) describes, are so complex that call upon a set of other concepts for their clarification. For example, as it is depicted in Figure 4, in order to illuminate the concept of 'knowledge' one has to appeal to the following concepts:

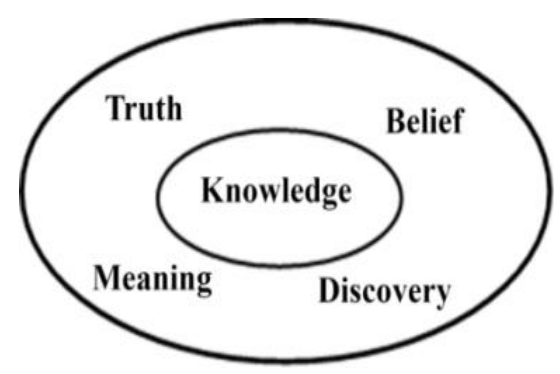

Figure 3. Description of 'knowledge' as a concept by other concepts (Adopted from Cam, 1995, p. 68)

Likewise, Paul and Elder (2012) comment that if someone asks us what 'friend' is, we might say, as the Webster's New World (2016) does, 'a person whom one knows well and is fond of.' If s/he keeps questioning what 'knowing someone well' means, we will explain that using further concepts.

\section{Facilitating Factors}

As concerns the facilitating factors, those who had produced open questions addressed that one of the effective factors which gave rise to their generating such types of questions was their innate disposition and nature. For instance, participant 8 stated: "Since childhood, I used to pay close attention to my surrounding objects, probe into phenomena, and ask deep questions."

They asserted that if individuals lack intrinsic potentiality of reflection and thoughtfulness, it may be difficult for them to notice concepts and see the deep layers of meaning. In this respect, Nosratinia and Sarabchian (2013) discovered that there is a relation between one's innate propensity and her/his sense of originality, thinking power, and imagination.

Another point smoothing the path towards raising open questions was being introvert and thinking a lot over different issues and relating what one reads or sees to her/his real life. Participant 11 stated that: "... and being introvert brought about privacy and peace of mind to me and as a result I could think more deeply." 
This is in line with what Dagostino (2016) mentions that introvert people prefer to be alone most of the time and therefore they have more chance to think and solve their own problems.

Another important factor they pointed out was the environment in which they were brought up. Participant 4 said that: "The books I read and the people I was in touch with, all influenced my way of thinking when I became an adult."

Plomin and Daniels (2011) came up with the point that environmental factors play a more dominant role than heredity in one's personality, psychopathology, and cognition. Bickhard (1992) argues that the environment and what takes place in that can have both microgenetic and developmental impact(s) on individuals.

Family was another crucial factor that had a robust effect on many respondents' thinking power. Participant 9, for instance, disclosed that:

"Since childhood, my parents bought thought-provoking story books for me and encouraged me to pay attention to the characters and the events which happened to them. When I asked my father a question, he would answer me reasonably and with patience."

In compliance with this point, Ornstein and Levine (2008) hold that family serves a substantial role in developing creative thinking ability in children.

The last factor which gave rise to students' thoughtfulness, as they maintained, was the particular method of teaching adopted by some teachers. According to them, a host of teachers, by making use of their sense of tolerance and creative techniques such as problem posing and solving activities in their teaching career, have been so constructive in broadening their students' thinking skills. Taneri (2012) argues that in order to develop pupils' creative thinking ability, teachers should themselves be enthusiastic and encourage parents to hone their children's creativity. All the above-mentioned factors can be summarized in Table 2 .

Table 2

Factors leading to raising and not-raising open (philosophical) question

\begin{tabular}{ll}
\hline \multicolumn{1}{c}{ Hindering Factors } & \multicolumn{1}{c}{ Facilitating factors } \\
\hline Memorization-based system & Innate disposition towards \\
Teacher-based & thinking \\
Text-based questions & Being introvert \\
Non-liberal atmosphere of classes & Thinking a lot \\
Tendency towards superficiality & Appropriate family \\
Unsuitable family environment & environment \\
Weak performance of mass media & Proper nurturing conditions \\
Irrational social customs & Adequate method of teaching \\
Reluctance to defining concepts & \\
\hline
\end{tabular}

Based on the factors presented, it can be inferred that depending on individuals, a single factor such as family, innate propensity, living condition, and social environment can be both hindering and facilitating.

\section{PBLT as a remedy}


Philosophy in ESL/EFL context has the potential to develop learners' philosophical thinking ability. In this vein, Philosophy-based Language Teaching (PBLT), introduced by Shahini and Riazi (2011), serves a substantial role. The core of this approach, which is founded on reflexive enquiry (Dewey, 1933), social enquiry (Vygotsky, 1984), and philosophical enquiry (Lipman, 1993), is to engage L2 learners in discussions that revolve around philosophical questions. The outcomes of this approach to boosting thinking and reasoning skills are as follows:

- exploring concepts

- sticking to the point

- exploring possibilities

- open-mindedness

- discovering criteria
- identifying logical relations

- asking logical questions

- making useful distinctions

- tolerating opposing ideas

- giving and seeking reasons

It should be noted that for improving EFL learners' philosophical mentality, PBLT can be employed as a resolution to the current problems reflected through hindering factors. In this student-based approach which creates a liberal democratized classroom in which all students have equal opportunity to voice their opinions, they are not simply funneled information but work together on rationale problem solving. The process of philosophical exploration in this approach encourages students to take responsibility for their own learning and to develop into independent and self-correcting learners. Besides, in such an approach the teachers do not pose authoritative views on the subjects. They, by asking open-ended questions, posing alternative views, seeking clarification, and questioning reasons, both guide and respect students and are always ready to learn from them. Additionally, in this approach, one should look for the texts which evoke natural curiosity and sense of wonder and puzzlement and invite the readers to plunge deeper and deeper into subjects. The contrast between the features differentiating the present and the desired status of philosophic-mindedness can be clearly listed in table 3 .

Table 3

The features leading to present and desired status of philosophic-mindedness

\begin{tabular}{ll}
\hline \multicolumn{1}{c}{ Present status } & \multicolumn{1}{c}{ Desired status (created by PBLT) } \\
\hline Routine thinking & Beyond-routine thinking \\
Memorization & Reflection \\
Teacher-based & Student-based \\
Text-based questions & Beyond-text based questions \\
Non-liberal atmosphere of classes & Democratized atmosphere of classes \\
Tendency towards superficiality & Propensity towards depth \\
No attention paid to concepts & Issues revolve around concepts \\
Indoctrination & Avoidance of indoctrination \\
Teacher is dominant and directive & Teacher is facilitator and conductor \\
Texts void of philosophical enquiry & Texts provoke philosophical perplexity \\
Unilateral teaching and learning & Bilateral teaching and learning \\
\hline
\end{tabular}

\section{CONCLUSION}

The finding that the majority of the participants were not able to generate open (literary speculation and enquiry/philosophical) questions may lead to the conclusion that they were in the habit of narrow and superficial thinking and that philosophical thinking might not be welcomed in the related context. Moreover, in this educational setting, learning might be defined as the mastery of knowledge and students may find that knowledge fruitful mostly for 
their exams and not for their lives. In addition, as Dewey (1983) mentions, for reflective thinking to thrive, a society must be open, pluralistic, and democratic. The educational system in the current EFL context based on the inhibiting factors such as non-liberal atmosphere, authority of government in mass media, etc. is reductionist taking away thinking and reasoning ability from students and pushing them toward rote learning and memorization. Another point which can be concluded is that an amalgamation of factors is contributing to raising and notraising open (philosophical) questions. For instance, for raising philosophical questions one single factor like individual's trait or innate propensity is not enough but other factors like family, social environment, and method of teaching are essential as well.

\section{IMPLICATIONS}

Firstly, this study may make policy makers aware of the barriers to philosophical thinking and set conditions for curriculum planners, syllabus designers, and teachers to assist students to view the issues philosophically in their own areas of specialization. Secondly, though there are few ways for investigating the status of philosophical mentality, the present technique of asking the readers to make question(s) on the texts and then analyzing their questions based on a) Cam's (2006) question framework and b) the characteristics of philosophical questions listed can be utilized for realizing philosophic-mindedness both in EFL contexts and other educational disciplines. Besides, philosophy as the 'Mother of Disciplines' has recently found its way into different fields of study and its application to various fields has resulted in philosophy of science, philosophy of language, philosophy of art, philosophy of education, etc. (Cam, 1995; Gregory, 2008; Lipman, 2003). Hence, the same technique can be implemented as a tool to check if philosophy is appropriately practiced in those disciplines. Thirdly, PBLT can be used as a remedy to obviate the obstacles enumerated in the hindering factors to philosophic-mindedness and to assist L2 learners to improve their philosophical thinking ability and reasoning skills.

\section{REFERENCES}

Bickhard, M. H. (1992). How does the environment affect the person. Children's Development within Social Contexts: Metatheory and Theory, Lawrence Erlbaum Associates, Mahwah, NJ, 63-92.

Cam, P. (1995). Thinking together: Philosophical enquiry for the classroom. Sydney, Australia: Primary English Teaching Association and Hale \& Iremonger.

Cam, P. (2006). 20 thinking tools. Victoria, Asutralia: ACER Press.

Cottrell, S. (2005).Critical thinking skills: Developing effective analysis and arguments. New York, NY: Palgrave Macmillan.

Dagostino, A. (2016, April 15). Study shows introverts are deep thinkers and geniuses. Retrieved from http://www.rebelcircus.com/blog/study- shows-introverts- deepthinkers- geniuses/

Dewey, J. (1933). How we think. Lexington, MA: D.C. Heath. 
Dewey, J. (1983). Democracy and education. New York, NY: MacMillan.

Duncan, G. J., and Brooks-Gunn, J. (Eds). (1997). Consequences of growing up poor, New York, NY: Russell Sage Foundation.

Gregory, M. (2008). Philosophy for children: A practitioner handbook. Montclair, NJ: Institute for the Advancement of Philosophy for Children.

Ghorbanalizadeh Ghaziani, F., Razavi, M., Khodaparast Sareshkeh, S., and Ghasemi, R. (2014). Preference of educational philosophy and philosophical mindedness of Iranian physical education and sport science lecturers. Annals of Applied Sport Science, 2(1), 81-86.

Hager, P., and Kaye, M. (1991). Critical thinking ability and teacher effectiveness. Higher Education Research and Development, 10(2), 177-186.

Hashim, R., Hussien, S., \& Imran, A. M. (2014). Ḥikmah (wisdom) pedagogy and students' thinking and reasoning abilities. Intellectual Discourse, 22(2).

Haynes, J. (2002). Children as philosophers: Learning through enquiry and dialogue in the primary classroom. London, England and New York, NY: Routledge.

Inggårde, K. (2014). Creativity and EFL learning: An empirical study in a Swedish uppersecondary school (Dissertation, Mälardalen University Sweden, Västerås and Eskilstuna, Sweden). Retrieved from http://urn.kb.se/resolve?urn=urn:nbn:se: mdh: diva-24884

Jie, Z. H. O. U., Yuhong, J. I. A. N. G., \& Yuan, Y. A. O. (2014). The investigation on critical thinking ability in EFL reading class. English Language Teaching, 8(1), 83-94.

Kennedy, D. (1992). Using Peter Rabbit as a Philosophical Text with Young Children. Analytic Teaching, 13(1), 53-58.

Kincheloe, J. L., and Weil, D. K. (2004). Critical thinking and learning: An encyclopedia for parents and teachers. London: Greenwood Press.

Ladan and Laleh Bijani. (n.d.) In Wikipedia. Retrieved July 25, 2016, from https://en.wikipedia.org/wiki/Ladan_and_Laleh_Bijani

Lipman, M. (1993). Thinking children and education. Dubuque, IA: Kendall/Hunt Publishing Company.

Lipman, M. (1988). Philosophy goes to school. Philadelphia: Temple University Press.

Lipman, M. (2003). Thinking in education ( $2^{\text {nd }}$ ed.). New York: Cambridge University Press.

Lipman, M., Sharp, A. M., and Oscanyan, F. (1980). Philosophy in the classroom (2 ${ }^{\text {nd }}$ ed.). Philadelphia, PA: Temple University Press.

Mead, G. H. (1934). Mind, self, and society: From the standpoint of a social behaviourist, Chicago: University of Chicago Press. 
Mollaei Nejad, A., and Zekavati, A. (2008). Comparative examination of teacher training syllabus system in England, Japan, France, Malaysia, and Iran. Quarterly Journal of Educational Innovations, 7(26), 35-62.

Nikkhah, A., M. (2008). The Philosophical Mentality and its Dimensions in Teachers and Sport Trainers in the City of Golpayegan. (Unpublished Master's thesis in Physical Education and Sports Science). Isfahan University, Isfahan, Iran.

Nouri, S., Fayyaz, I., and Seif, A. (2013). Effect of Philosophical Mentality on Solving Math Problems by Male and Female Third-grade Students in Hamedan Junior High Schools. Thinking and child, 4(7), 121-139.

Nosratinia, M., and Sarabchian, E. (2013). The role of personality traits in predicting EFL learners' critical thinking skills: A study on psychological characteristics of EFL learners. IOSR Journal of Humanities and Social Sciences, 13(6), 89-93.

Orlich, D., Harder, R., Callahan, R., Trevisan, M., and Brown, A. (2010). Teaching strategies: A guide to effective instruction. Boston: Wadsworth Publishing.

Ornstein, A.C., and Levine, D.U. (2008). Foundations of education (10 ${ }^{\text {th }}$ Ed.). Boston, MA: Houghton Mifflin.

Paul, R., and Elder, L. (2005). A guide for educators to critical thinking competency standards, California, CA: Foundation for critical thinking.

Paul, R., and Elder, L. (2012). Critical thinking: Tools for taking charge of your learning and your life ( $3^{\text {rd }}$ ed.), New Jersey: Prentice Hall.

Plomin, R., and Daniels, D. (2011). Why are children in the same family so different from one another? International Journal of Epidemiology, 40(3), 563-582.

Potter, B. (1902). The tale of Peter rabbit. Retrieved from http://etc.usf.edu/lit2go/148/peterrabbit-and-other-stories/ 4923 /the-tale-of-peter-rabbit/

Preece, A. S. (2013). Make it mean! Using a community of enquiry to improve language skills in the ESL classroom. IIUM Journal of Educational Studies, 1(1), 25-54.

Russell, B. (1997). The problems of philosophy. New York, NY: Oxford University Press.

Shahini, G. H., and Riazi, A. M. (2011). A PBLT approach to teaching ESL speaking, writing, and thinking skills. ELT Journal, 65(2), 170-179.

Smith P. G. (1956). Philosophic-mindedness in educational administration. Columbus: Ohio State University.

Smith, G. P. (1965). Philosophy of education: Introductory studies. New York, NY: Harper and Row Publishers.

Soltani, I. (1996). Measuring philosophical mentality of managers. Journal of Tadbir, 62, 1619. 
Splitter, L., and Sharp, A. M. (1995). Teaching for better thinking: The classroom community of enquiry. Hawthorn, Victoria: Australian Council for Educational Research.

Talebpour, M., Hosseini, A., Jabari, H., and Jabari, M. (2005). Study and comparison of philosophic-mindedness of sports teams managers, coaches, and supervisors in Iran universities. Research on Sport Sciences, 3(7), 109-130.

Taneri, P. O. (2012). Roles of parents in enhancing children's creative thinking skills. Journal of Human Sciences, 9(2), 91-108.

Vygotsky, L. (1984). Thought and language. Cambridge: MIT Press.

Webster's New World Dictionary (2016). USA: Massachusetts, Springfield. 


\section{Appendix A}

\section{The Tale of Peter Rabbit: A Summary}

There were four little Rabbits and their names were: Flopsy, Mopsy, Cotton-tail and Peter. They lived with their mother. Mrs. Rabbit one morning said: 'You can go into the fields but don't go into McGregor's garden: your father had an accident there.' Flopsy, Mopsy, and Cottontail went to gather blackberries but Peter ran away to McGregor's garden. He ate some fruits. On his way, he met McGregor who was planting cabbages. He jumped up and ran after Peter, waving a rake and calling out, 'Stop thief!' Peter was most dreadfully frightened for he had forgotten the way back to the gate. After a while, McGregor was tired of running after Peter. Peter sat down to rest; he was out of breath and trembling with fright but did not know which way to go. He asked the way to the gate from a mouse which was carrying peas. She only shook her head at him. Then, Peter started running as fast as he could. McGregor caught sight of him again but Peter did not care and could be safe at last in the wood outside the garden. Peter was so tired, hungry, and frightened when he got home but Flopsy, Mopsy, and Cottontail had bread, milk, and blackberries for dinner. 


\section{Appendix B}

\section{Ladan and Laleh Bijani}

Ladan Bijani (January 17, 1974 - July 8, 2003) were Iranian Law graduates. They were conjoined twin sisters, joined at the head, who died after their complicated surgical separation. They were born in Shiraz, a city in southwest Iran. The Bijani sisters were lost in a hospital. The Bijanis' parents did not find them until several years later in Karaj, where Dr. Alireza Safaian had adopted them. Even though their father won the possession against Safaian, the sisters chose to spend their childhood with Safaian.

They studied Law for four years at Tehran University. They faced some difficulties because of their conjoined nature. Since they had to study together, they needed to choose a common working path. Ladan wanted to be a lawyer, while Laleh wished to become a journalist; in the end, they agreed on Ladan's choice. Most other personal decisions also had to meet each other's approval. For these and other reasons, they had wanted to be separated since they were children. Laleh hoped that she could then move to Tehran, the capital city of Iran, to study journalism, while her sister continued with graduate studies in law and then moved to Shiraz. In addition, the sisters had different hobbies. While Laleh liked to play computer games, Ladan preferred computer programming. Ladan also described her sister as more introverted and herself quite talkative.

In 1996, they traveled to Germany, trying to get doctors there to separate them; the German doctors however rejected to operate, saying that the risk of separation surgery would be too high for both of them. In November 2002, the Bijani sisters traveled to Singapore. Even though they were warned by the doctors that the surgery to separate them would still be very risky, the sisters were very determined.

After seven months in the Southeast Asian country, they went to the operating table under the care of a large team of international specialists, composed of 28 surgeons and more than 100 support staff. The attempt to separate the twins turned out to be difficult, because their brains not only shared a major vein but had fused together. The separation was achieved on July 8, 2003, but it was announced then that the twins were in critical condition, both having lost a large volume of blood due to complications of the operation.

The separation stage of the surgery completed at 13: 30. Ladan died at around 14:30 and her sister Laleh died a short time afterwards at 16: 00. The sisters were buried in separate tombs, side by side in Lohrasb. The sisters willed their property to blind and orphaned children. and Laleh 